\title{
Identification of an interchromosomal compartment by polymerization of
}

\section{nuclear-targeted vimentin}

\author{
Joanna M. Bridger ${ }^{1}$, Harald Herrmann², Christian Münkel ${ }^{3}$ and Peter Lichter ${ }^{1, *}$ \\ ${ }^{1}$ Organization of Complex Genomes, ${ }^{2}$ Division of Cell Biology and ${ }^{3}$ Biophysics of Macromolecules, German Cancer Research \\ Center, Im Neuenheimer Feld 280, D-69120 Heidelberg, Germany \\ *Author for correspondence (e-mail: p.lichter@dkfz-heidelberg.de)
}

Accepted 18 February; published on WWW 20 April 1998

\section{SUMMARY}

A number of structural and functional subnuclear compartments have been described, including regions exclusive of chromosomes previously hypothesized to form a reactive nuclear space. We have now explored this accessible nuclear space and interchromosomal nucleoplasmic domains experimentally using Xenopus vimentin engineered to contain a nuclear localization signal (NLS-vimentin). In stably transfected human cells incubated at $37^{\circ} \mathrm{C}$, the NLS-vimentin formed a restricted number of intranuclear speckles. At $28^{\circ} \mathrm{C}$, the optimal temperature for assembly of the amphibian protein, NLSvimentin progressively extended with time out from the speckles into strictly orientated intranuclear filamentous arrays. This enabled us to observe the development of a system of interconnecting channel-like areas. Quantitative analysis based on 3-D imaging microscopy revealed that these arrays were localized almost exclusively outside of chromosome territories. During mitosis the filaments disassembled and dispersed throughout the cytoplasm, while in anaphase-telophase the vimentin was recruited back into the nucleus and reassembled into filaments at the chromosome surfaces, in distributions virtually identical to those observed in the previous interphase. The filaments also colocalized with specific nuclear RNAs, coiled bodies and PML bodies, all situated outside of chromosome territories, thereby interlinking these structures. This strongly implies that these nuclear entities coexist in the same interconnected nuclear compartment. The assembling NLS-vimentin is restricted to and can be used to delineate, at least in part, the formerly proposed reticular interchromosomal domain compartment (ICD). The properties of NLS-vimentin make it an excellent tool for performing structural and functional studies on this compartment.

Key words: Chromosome territory, Nuclear organization, Interchromosomal domain, Nuclear localization signal, Vimentin, Intermediate filament

\section{INTRODUCTION}

It is becoming increasingly evident that the nucleus is a highly organized, dynamic structure and that specific compartments are present which exclusively contain accumulations of proteins, specific species of RNA or chromosomes. The nucleolus is the most obvious nuclear compartment, containing the ribosomal RNA genes and a number of nucleolar specific proteins (for review see Thiry and Goessens, 1992; Scheer and Weisenberger, 1994). There are also a variety of different interchromatin nuclear bodies containing specific proteins, these include coiled bodies (for review see Lamond and Carmo-Fonseca, 1993; Roth, 1995), PML bodies also known as ND10 domains (Ascoli and Maul, 1991; Daniel et al., 1993) and interchromatin granules (Fakan et al., 1984; Spector et al., 1991; Visa et al., 1993). Sites of active transcription are also distributed in a number of nuclear foci, visualized either by incorporation of labeled nucleotides or by the distribution of specific proteins involved in transcription (Carter et al., 1991; Jackson et al., 1993; Wansink et al., 1993; Huang et al., 1994).
Usually these sites are associated with the non-extractable part of the nucleus termed the nuclear matrix/nucleoskeleton (Jackson et al., 1993).

Specific species of RNA have been found in accumulations, either spherical or track-like in morphology (Lawrence et al., 1989; Raap et al., 1991; Xing et al., 1993; Jiménez-Garcia and Spector, 1993). The transcripts contained within some of these RNA structures appear to have been released from a discrete genomic site (Xing et al., 1995; Dirks et al., 1997; Lampel et al., 1997). The morphology of such RNA signals suggests that the released transcripts are channeled within the nucleoplasm. Elongated accumulations of RNA derived from the EBV genome in Namalwa cells are preserved in nuclei after nuclear matrix preparations (Xing and Lawrence, 1991), indicating that messenger RNA is part of the non-extractable nuclear matrix. It remains undetermined as to how these spatial isolations of nuclear entities are generated. It is still debated whether there are underlying rigid networks in interphase nuclei which anchor nuclear components, or whether the maintenance of nuclear 
structure is mediated via a more dynamic system (for an overview see Berezney and Jeon, 1995).

Giant chromosomes in Drosophila salivary gland nuclei occupy distinct spatial domains and are separated from one another indicating that these specialized chromosome structures, visualized by DNA stains, are not intermingled (Gruenbaum et al., 1984; Hochstrasser et al., 1986). With the introduction of in situ hybridization (ISH), especially fluorescence ISH (FISH), whole individual chromosomes were delineated within higher eukaryotic interphase nuclei confirming their territorial organization (for review see Lichter et al., 1991). Delineation of targeted nucleic acids and proteins in cellular preparations by ISH and immunolocalization, respectively, added a new dimension to the analysis of nuclear architecture. It has been shown that single species of RNA are virtually always located immediately outside of the chromosome the RNA originated from (Zirbel et al., 1993; Clemson et al., 1996). Furthermore, concentrations of splicing components visualized by Sm antigen staining were also found to reside outside of chromosome territories (Zirbel et al., 1993; the term chromosome territory was coined to distinguish the area/space occupied by an individual chromosome from domains, which could be subchromosomal). In a complementary study, it was shown that active and inactive genes are preferentially situated at the borders of chromosome territories (Kurz et al., 1996). Based on these and other data, a model was proposed whereby chromosomes are confined to territories with a functional channel-like space between them, into which genes from the surface of chromosomes are transcribed and the resulting RNA released, spliced and transported to the nuclear envelope for export (Zirbel et al., 1993; Cremer et al., 1993; Kurz et al., 1996). This putative functional space between chromosomes has been termed the interchromosomal domain (ICD) compartment (Zirbel et al., 1993). An interchromosomal space was also proposed after a detailed electron microscopic study of the organization of chromosomes through the cell cycle (Chai and Sandberg, 1988). The existence of this space between chromosomes as a defined nuclear compartment, however, remains an assumption.

Thus, up to the present day, only endogenous nuclear components have been observed extrachromosomally. In order to study the existence and extent of the extrachromosomal space, we have been analyzing exogenous compounds experimentally introduced into cell nuclei. We report here the use of a recombinant cytoplasmic protein, vimentin, engineered to translocate into the nucleus and to form filaments therein, thus serving as a marker for nuclear regions devoid of chromatin. Vimentin is a type III intermediate filament protein and it characteristically only polymerizes into filamentous structures within the cytoplasm (for comprehensive reviews see Quinlan et al., 1995; Stewart, 1993). In the case of Xenopus vimentin, it has been found that this amphibian protein is remarkably thermosensitive and hardly ever forms intermediate filaments at $37^{\circ} \mathrm{C}$ (Herrmann et al., 1992, 1993). Therefore, mammalian cells, transfected with Xenopus vimentin cDNA or microinjected with recombinant protein, display large aggregates of vimentin at the $37^{\circ} \mathrm{C}$ (nonpermissive temperature). When cells are shifted to $28^{\circ} \mathrm{C}$ (permissive temperature) aggregates rapidly appear to reorganize into fibrillar arrays from the centers of aggregation. Similarly, after transfection with Xenopus vimentin cDNA containing a nuclear localization signal (NLS), which was introduced by site-directed mutagenesis, the NLS-vimentin was transported efficiently into the nucleus and, at $28^{\circ} \mathrm{C}$, was assembled into distinct, long filamentous arrays (Herrmann et al., 1993). The reason for the restricted growth within the nucleus of the vimentin filaments, apparently interconnecting the nuclear aggregates, remained, however, elusive.

In the present study, cells of the vimentin-free human line SW13 were stably transfected with NLS-vimentin cDNA. Following a shift to the permissive temperature $\left(28^{\circ} \mathrm{C}\right)$ vimentin filamentous arrays were observed restricted to a distinct nuclear region. In order to elucidate the organization of these arrays in the context of nuclear subcompartments, the filaments were visualized simultaneously, in spatially well preserved nuclei, with chromosome territories, with nuclear RNA and with certain nuclear bodies. Three-dimensional reconstructions of serial confocal optical sections through nuclei uncovered the topological confinement of the NLSvimentin filamentous arrays in a nuclear subcompartment and their spatial relationship with chromosome territories.

\section{MATERIALS AND METHODS}

\section{Cell culture and transfection}

SW13 human adrenal cortex carcinoma cells (Hedburg and Chen, 1986) were cotransfected with a plasmid p163/7 Xen-Vim (SacIINLS) 'NLS-vimentin' and a plasmid containing the neomycin resistance gene using conventional calcium phosphate methods (see Herrmann et al., 1992, 1993). Stable cell lines expressing Xenopus vimentin in the nucleus were obtained by growing transfected cells in the presence of $0.4 \mathrm{mg} / \mathrm{ml}$ geneticin for extended times. Subclones were generated by serial dilution and growth in the presence of $50 \%$ conditional medium.

SW13 clone 14 cells and human dermal fibroblasts, strain 1HD (derived from a juvenile foreskin), were grown in Dulbecco's modified Eagles medium containing 10\% newborn calf serum (NCS) (v/v) and antibiotics. SW13 cells were maintained at $37^{\circ} \mathrm{C}$ and, when desired, transferred to $28^{\circ} \mathrm{C}$.

\section{Cell preparation, fixation and permeabilization}

Spreads of metaphase SW13 cells were obtained according to standard protocols using hypotonic treatment and methanol:acetic acid fixation. Interphase cells for FISH analyses were fixed and permeabilized according to protocols reported elsewhere (Zirbel et al., 1993; Kurz et al., 1996; Bridger et al., 1997) which have been shown to preserve the three-dimensional organization of nuclei (see Kurz et al., 1996). Cells were washed in phosphate buffered saline (PBS) and fixed in $4 \%$ paraformaldehyde for 20 minutes at room temperature. Following fixation, cells were permeabilized with $0.5 \%$ (v/v) TritonX 100 and $0.5 \%$ (w/v) saponin in PBS, for 20 minutes. Cells were then incubated in $20 \%(\mathrm{v} / \mathrm{v})$ glycerol for at least 30 minutes and frozen in liquid nitrogen. In the frozen state, cells were transferred to $-80^{\circ} \mathrm{C}$ for storage. When required, slides were allowed to thaw slowly at room temperature and then washed in PBS prior to a 10 minute incubation in $0.1 \mathrm{M} \mathrm{HCl}$. For chromosomal painting by FISH, cells were repeatedly frozen in liquid nitrogen and thawed (up to 5 times), followed by a final wash in PBS prior to denaturation. Chromosome painting probes were used to delineate chromosomes $1,4,8$ and 13 (Collins et al., 1991; a kind gift from Prof. J. Gray, University of California San Francisco). Xenopus vimentin RNA was delineated by plasmid p163/7 Xen-Vim (SacII-NLS). Probes were labeled by nick translation incorporating biotin- or digoxigenin-nucleotides (Lichter et al., 1990). Probe DNAs were combined with $7 \mu \mathrm{g}$ salmon sperm 
Fig. 1. Immunolocalization of Xenopus vimentin visualized by monoclonal antibodies in human SW13 cells, clone 14 , stably transfected with a construct coding for Xenopus vimentin engineered to contain a nuclear localization signal. (A-C) Light microscopic analyses of transfected SW13 cells $\left(\mathrm{A}, \mathrm{A}^{\prime}\right.$ : conventional photographs, $\mathrm{B}$ : confocal laser scanning microscopy image, $\mathrm{C}$ : a CCD derived image). (A, $\left.\mathrm{A}^{\prime}\right)$ Overview of SW13 clone 14 cells. The cells have been incubated at $28^{\circ} \mathrm{C}$ for 40 minutes (A) and for 2.5 hours $\left(\mathrm{A}^{\prime}\right)$, respectively. Note the progressive formation of nuclear vimentin filaments upon temperature shift. Vimentin was visualized by a monoclonal antiXenopus vimentin antibody (XLVIM-14.13) followed by a Texas Red-conjugated secondary antibody. Note the variable expression of vimentin within a given a cell population. (B) A single SW13 cell nucleus delineated by DAPI staining (blue) and containing vimentin filaments visualized by XL-VIM14.13 antibody and a TRITCconjugated secondary antibody (red). Chromosome 4 sequences were visualized by FISH using a biotinylated chromosome 4 specific painting probe detected with avidin-FITC (green). (C) A CCD image of a nucleus in which double indirect

immunofluorescence has been performed, in combination with FISH, visualizing the nuclear vimentin in red, the nuclear periphery with a commercial human autoimmune serum reacting with nuclear rim antigens via AMCA-conjugated secondary antibody in blue and territories of chromosome 4 in green.

(D-F) Immunoelectron

microscopic analyses of the localization of NLS-vimentin using XL-VIM-14.13 followed by gold-coupled goat anti-mouse antibodies. (D) A thin-section of a SW13 cell nucleus which has been incubated at $37^{\circ} \mathrm{C}$. The gold labeling shows the vimentin in rounded aggregates (arrows).

(E) A nucleus of a cell incubated at $28^{\circ} \mathrm{C}$, at which temperature NLS-vimentin forms intranuclear filaments, building up into large immunopositive elongated filamentous structures (arrows). (F) A high resolution immunoelectron microscopy image of a vimentin fibre bundle comprised of loosely packed individiual filaments. Preparations were subjected to a slight silver enhancement. ne, nuclear envelope. Brackets indicate the position of an intranuclear filamentous array of NLS-vimentin. Bars: $10 \mu \mathrm{m}(\mathrm{A}) ; 5 \mu \mathrm{m}(\mathrm{B}-\mathrm{E}) ; 500 \mathrm{~nm}(\mathrm{~F})$
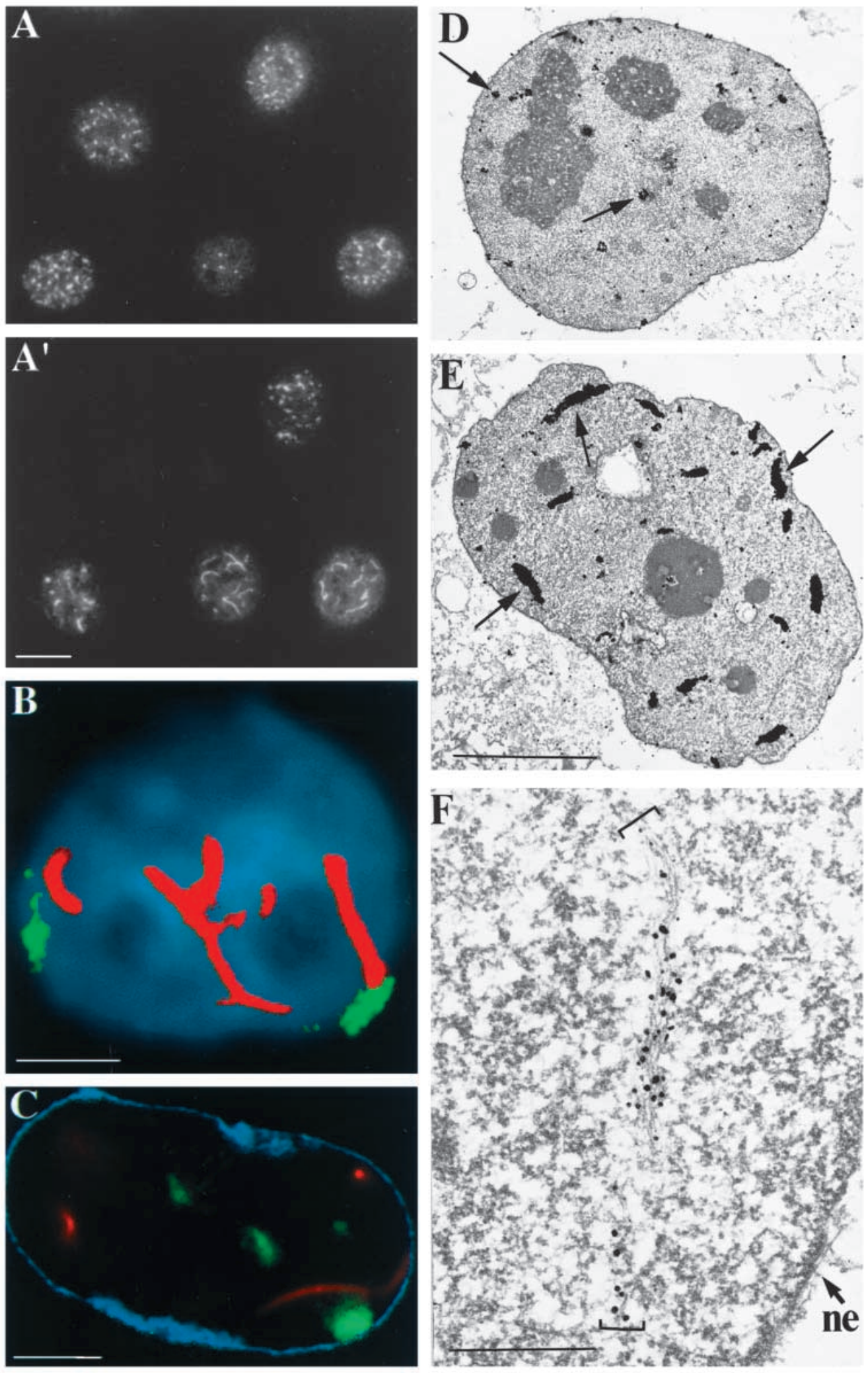
DNA, $3 \mu \mathrm{g}$ of the $\mathrm{C}_{0} \mathrm{t}-1$ fraction of human DNA and then precipitated at $-80^{\circ} \mathrm{C}$, dried and resuspended in $10 \mu \mathrm{l}$ hybridization cocktail (Lichter et al., 1990).

\section{Fluorescence in situ hybridization}

To visualize RNA only, cells were denatured in $40 \%$ formamide, $2 \times$ sodium saline citrate (SSC), $\mathrm{pH} 7.0$, for 2 minutes at $70^{\circ} \mathrm{C}$. For delineation of DNA sequences cells were denatured at $73^{\circ} \mathrm{C}$ to $75^{\circ} \mathrm{C}$ in $70 \%$ deionized formamide, $2 \times \mathrm{SSC}, \mathrm{pH} 7.0$, for 3 minutes and then immediately transferred to $50 \%$ deionized formamide, $2 \times \mathrm{SSC}, \mathrm{pH}$ 7.0, for 1 minute at the same temperature. Probes were denatured at $75^{\circ} \mathrm{C}$ for 5 minutes and then placed at $37^{\circ} \mathrm{C}$ for at least 10 minutes after denaturation to allow preannealing. $10 \mu \mathrm{l}$ of probe was applied to denatured cells and hybridized overnight at $37^{\circ} \mathrm{C}$.

Washes and detection of hybridized probe were performed (see Lichter et al., 1991) with a final wash in $0.1 \times \mathrm{SSC}$ at $60^{\circ} \mathrm{C}$. Biotinylated probes were detected using either $10 \mu \mathrm{g} / \mathrm{ml}$ cyanine- 3 conjugated to streptavidin or fluorescein isothiocyanate (FITC) conjugated to avidin in $4 \times$ SSC containing $1 \%$ BSA (w/v). Digoxigenin labeled probes were detected via sheep anti-digoxigenin antibody conjugated to tetramethylrhodamine isothiocyanate (TRITC). Following incubation at room temperature for 1 hour, slides were washed at $42^{\circ} \mathrm{C}$ in $4 \times$ SSC containing $0.1 \%$ Tween-20 (v/v) for 15 minutes with 3 changes of buffer.

\section{Immunofluorescence}

After detection of DNA via incorporated reporter molecules, monoclonal anti-Xenopus vimentin antibody XL-VIM-14.13 (Herrmann et al., 1996; Progen, Heidelberg, Germany) was incubated for 1 hour at room temperature or overnight at $4^{\circ} \mathrm{C}$. To visualize this monoclonal antibody, a secondary antibody, goat anti-mouse conjugated to TRITC, was incubated at room temperature for 1 hour. For double indirect immunofluorescence analyses guinea pig antivimentin, raised against recombinant Xenopus vimentin, was used in combination with: (i) monoclonal anti-p80 coilin antibody (a kind gift from M. Carmo-Fonseca and A. Lamond, University of Dundee, UK) used 1:100 in PBS containing 1\% newborn calf serum (NCS), and (ii) anti-PML (5E10) antibody (a kind gift from R. van Driel, University of Amsterdam, NL; Stuurman et al., 1992) used 1:500 in PBS/1\% NCS. The guinea pig anti-Xenopus vimentin was revealed with rabbit anti-guinea pig secondary antibody conjugated to TRITC. The monoclonal antibodies were revealed with goat anti-mouse conjugated to FITC. In the 3 color CLSM experiments the vimentin was detected by goat anti-mouse conjugated to cyanine-5 (Sigma Chemical Co., München, FRG). To delineate the nuclear periphery, a commercial human autoimmune serum reacting with a nuclear rim antigen (The Binding Site, Heidelberg, Germany) was employed which was detected via a goat anti-human antibody conjugated to AMCA. Xenopus vimentin was also revealed using a goat anti-mouse antibody conjugated to cyanine-5 (Sigma, Munich, Germany). All antibody incubations were performed at room temperature for 1 hour in a humid chamber. Slides were mounted in Vectashield (VectaLabs, Lamont, USA). Two color confocal images were collected on a Zeiss 310 CLSM using a $\times 63$ objective and laser lines $488 \mathrm{~nm}$ and $543 \mathrm{~nm}$ for excitation of FITC and TRITC/cyanine 3, respectively. Three color CLSM images were obtained on a Zeiss 410 LSM using a $\times 40$ objective and laser lines $364 \mathrm{~nm}, 488 \mathrm{~nm}, 543 \mathrm{~nm}$ and $633 \mathrm{~nm}$ for excitation of DAPI, FITC, TRITC and cyanine-5, respectively. Pinhole size, gain and contrast values were selected for optimal quality of images. All evaluations were performed using multiple series of optical sections through cells. Cells were sectioned at $0.5 \mu \mathrm{m}$ increments and TRITC, FITC and cyanine-5 images were acquired simultaneously for each plane. The DAPI images in the 3 color CLSM analyses were acquired separately. Images were either photographed from the color monitor or printed on a dye sublimation printer. For some 2-D analyses (Figs 1 and 3) images were acquired separately using a cooled charge coupled device camera (CCD, Photometrics,
Tucson, AZ, USA), electronically overlaid and aligned. Threedimensional reconstructions of two color CLSM optical sections (vimentin and chromosome territories) were performed using software based on public domain volume rendering library VolPack (Lacroute and Levoy, 1994). In the three-dimensional reconstructions, approximately $15 \%$ of the maximum intensity was removed by thresholding.

\section{Electron microscopy}

Immunoelectron microscopy was performed essentially as described by Blessing et al. (1993). Fixation of cells was for 1 to 2 minutes with $2 \%$ formaldehyde (v/v) in PBS followed by detection of Xenopus vimentin employing hybridoma supernatants of monoclonal antibody XL-VIM-14.13.

\section{RESULTS}

\section{Exogenous Xenopus vimentin located in nuclei forms a filamentous system organized outside of chromosome territories}

In order to analyze nuclear space accessible for filamentous structures and its relationship with chromosome territories, we transfected vimentin-free cell lines with nuclear-targeted vimentin. Transfection was performed with the plasmid p163/7 Xen-Vim (SacII-NLS) containing the Xenopus vimentin cDNA with a lamin B-like NLS introduced by site-directed mutagenesis (Herrmann et al., 1993). In transient transfection experiments using two essentially vimentin-free cell lines, human breast adenocarcinoma derived MCF-7 cells and human adrenal cortex carcinoma SW13 cells, nuclear filamentous systems of NLS-vimentin were observed at the appropriate temperature. Although chromosomal painting in transiently transfected cells was possible, the fraction of cells which contained both high quality FISH signals and extensive arrays of nuclear vimentin was low (due to the small fraction of transfected cells). Therefore, stable clones were established and one, termed SW13 clone14, was used for the analyses.

The amphibian vimentin is thermosensitive and therefore does not assemble into filaments at $37^{\circ} \mathrm{C}$. Correspondingly, the NLS-vimentin forms numerous nuclear aggregates at this temperature. These aggregates were globular in morphology, usually approximately $0.6 \mu \mathrm{m}$ in diameter, as estimated from conventional as well as immunoelectron micrographs (Fig. 1D). However, when cells were incubated at $28^{\circ} \mathrm{C}$, within $1-3$ hours after the temperature shift filamentous structures appreared to grow out from the aggregates (Fig. 1A, $\mathrm{A}^{\prime}$ ). Incubations longer than 4 hours yielded extended NLSvimentin filamentous arrays with no apparent aggregates remaining (Fig. 1B,C,E,F). Therefore, cells were maintained at $37^{\circ} \mathrm{C}$ and placed at $28^{\circ} \mathrm{C}$ for at least 6 hours to allow the vimentin aggregates to extend fully into filamentous structures.

In order to visualize intermediate filaments together with individual chromosomes, cells were fixed in $4 \%$ paraformaldehyde for 20 minutes and permeabilized using a protocol which permitted the three-dimensional structure of the cells to be retained (see Materials and Methods). Individual chromosome territories and NLS-vimentin filaments were codelineated by FISH and indirect immunofluorescence, respectively. NLS-vimentin structures and chromosome territories appear to exist in different nuclear subcompartments (Fig. 1B and C). There appeared to be no difference in 
morphology of vimentin filamentous arrays in cells prepared for FISH as compared to those in conventionally fixed cells (see Fig. 1 $\mathrm{A}^{\prime}$ and Herrmann et al., 1993).

Vimentin intermediate filament staining did not extensively overlap with the anti-nuclear rim signal (Fig. 1C) or the nuclear envelope as demonstrated by immunoelectron microscopy (Fig. 1E). Thus, the NLS-vimentin protein did not incorporate into the nuclear lamina. Since the fluorescence images suggested that the vimentin filaments occupied large expanses of the nucleus, their dimensions were assessed independently by electron microscopy (Fig. $1 \mathrm{E}$ and F). The individual filaments were not tightly packed but formed loose bundles, organized in parallel (see Fig. 1F). The width of the filamentous arrays seen by electron microscopy ranged from $0.1 \mu \mathrm{m}$ to $0.3 \mu \mathrm{m}$ and in confocal laser scanning microscopy (CLSM) images from $0.3 \mu \mathrm{m}$ to $0.7 \mu \mathrm{m}$. The difference in the measurements from the two methods is due to an apparent increase in object size from the application of two layers of antibodies intrinsic to indirect immunofluorescence methodology and to the dilatation of fluorescence signals.

In order to analyze the spatial relationship of nuclear vimentin with chromosome territories in detail, chromsomes 1 , 4, 8 and 13 were delineated individually in interphase SW13 cell nuclei by FISH and vimentin filaments were covisualized by indirect immunofluorescence. SW13 is a tumor cell line, which has been in culture for a number of years and, as a consequence, has many chromosomal rearrangements and aneuploidies. Therefore, the size and number of chromosomes and chromosomal regions stained by each chromosome painting probe were first assessed by FISH on spreads of metaphase cells. It was found that the probe for chromosome 1 labeled four derivative chromosomes (one completely, two almost completely and one partially painted, Fig. 2A), the probe for chromosome 4 painted one apparently normal chromosome 4 in addition to one small marker chromosome and a rearranged chromosome containing chromosome 4 material (Fig. 2C), the probe for chromosome 8 painted two individual chromosomes in addition to four segments contributing to four rearranged chromosomes (Fig. 2E) and the probe for chromosome 13 labeled two apparently normal copies of chromosome 13 (Fig. 2G).

Interphase cells, in which chromosome territories and vimentin had be delineated, were analyzed by CLSM. Cells were sectioned at $0.5 \mu \mathrm{m}$ increments (see Fig. 3A). Threedimensional reconstructions of confocal optical sections were produced using a recently developed computer software programme, allowing the positioning of the vimentin, with respect to chromosome territories, to be observed easily. Furthermore, the continuous vimentin filament system of threedimensional loops and curves could be viewed as a whole structure (Fig. 2B,D,F,H). The filamentous stuctures follow the contours of specific chromosome territories and they can even be observed between two adjacent territories (Fig. 2D).

The intranuclear positioning of the vimentin filaments compared to the location of the chromosome territories was assessed in the following way. Confocal optical mid-sections of painted chromosome signals were used to segment the delineated chromosome territory and the immediate surrounding region. The territory was outlined and concentric segments created by: (i) decreasing the outline by 3 pixels ( 260 $\mathrm{nm}$, half the mean diameter of a subset of the largest vimentin filamentous structures) thus creating two segments within the territory, numbered 1 and 2, and (ii) by expanding the outline by 3 pixels giving a further segment numbered 3 , representing the area immediately adjacent to the territory (Fig. 3B). Segments 2 and 3 combined represent the periphery of the chromosome and segment 1 the interior, thus dividing the chromosome territory into two regions, interior and periphery. As determined by area measurements on a subset of the segmented territories, the interior and the periphery regions represented approximately $50 \%$ of the area of the territory in any one optical section. It should be stressed that the analysis procedure was biased against our working hypothesis, since vimentin signals were scored to reside in the chromosome interior even when only one pixel of the vimentin signal entered segment 1, despite knowing that the underlying structure was smaller in diameter (see above, Fig. 1).

The distributions of vimentin within the segmented territories are displayed graphically in Fig. 3C. The numbers of territories analyzed for each chromosome type ranged from $65-82(n=304)$. Vimentin was situated at the periphery of chromosome territories in $78-88 \%$ of cases; while in $12-22 \%$, vimentin was located in the interior region of the chromosomes. Vimentin signals which are scored in the interior area might be colocalized with the FISH signals due to the limited $z$-axis resolution of confocal microscopy, however, the strong deviation from a random distribution revealed a predominant peripheral/extrachromosomal localization. Thus, these data provide evidence that the nuclear vimentin filaments are indeed localized extrachromosomally.

To further confirm that vimentin filaments are situated in an interchromosomal compartment, two chromosomes, either chromosomes 1 and 8 or chromosomes 4 and 13 were codelineated in the same three-dimensionally preserved nuclei and nuclear vimentin filaments were immunostained. Each entity was labeled with a specific fluorescence-coupled reagent and cells were analyzed by CLSM, acquiring images for all three fluorescence labels simultaneously. As shown in Fig. 4, vimentin bundles could be found inbetween two delineated chromosome territories. Thus, NLS-vimentin can polymerize in an extrachromosomal nuclear compartment which restricts its distribution to an apparently channel-like space between chromosomes.

\section{Colocalization of vimentin filaments and nuclear components residing outside of chromosome territories}

We observed that vimentin filaments organize outside of chromosome territories, and therefore we performed colocalization studies with other nuclear components which are known to localize outside of chromosome territories. This was to determine whether vimentin filaments are situated in the same or a different nuclear compartment as RNA accumulations and nuclear bodies. Previous studies demonstrated that accumulations of specific RNA species are situated outside of chromosome territories (Zirbel et al., 1993; Clemson et al., 1996). Thus, colocalization experiments between vimentin filaments and RNA expressed from the integrated Xenopus vimentin cDNA by FISH, were performed. We chose Xenopus vimentin RNA since, due to its high abundance in the nucleus, it provided an efficient target for FISH. In some cells the Xenopus vimentin RNA was 
Fig. 2. Distribution of chromosomal paints in spreads of metaphase chromosomes and in threedimensional reconstructions of interphase nuclei based on serial confocal sections. (A,C,E,G) Spreads of metaphase chromosomes after hybridization with FISH painting probes for chromosomes 1, 4, 8 and 13 in green, respectively, and counterstained with DAPI. (B,D,F,H) Three-dimensional

reconstructions, using public volume rendering software, of confocal sections taken at $0.5 \mu \mathrm{m}$ increments through nuclei with filamentous vimentin in red and territories of chromosomes 1,4 , 8 and 13 in green. The three-dimensionally reconstructed interphase nuclei $(\mathrm{B}, \mathrm{D}, \mathrm{F}, \mathrm{H})$ are displayed at approximately $3 \times$ higher magnification as compared to the metaphase spreads (A,C,E,G). Note that the painted segments of metaphase chromosomes and interphase territories correlate in number and that vimentin filament arrays traverse the nucleus extrachromosomally. Bar, $5 \mu \mathrm{m}$.
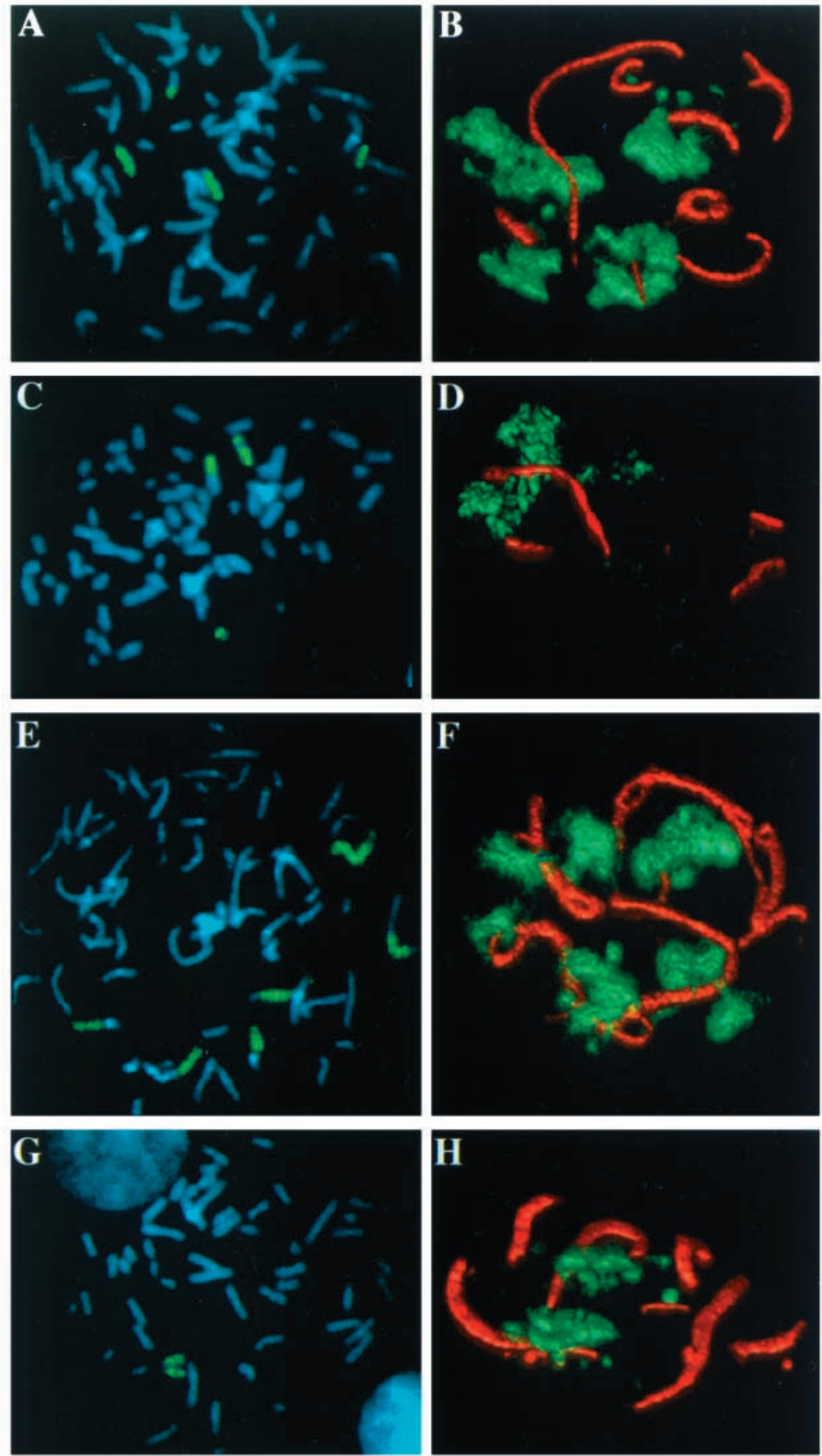

distributed as a discontinuous curvilinear array, very similar to the morphology of the vimentin structures (data not shown). Analysis by CLSM revealed colocalization between Xenopus vimentin RNA and vimentin filaments as shown by the yellow coloration resulting from the complete overlap of red and green signals (Fig. 5A). It has been observed that not only RNA resides outside of chromosome territories but that accumulations of splicing snRNPs, such as in coiled bodies, were also extrachromosomal in a number of cell types (Zirbel et al., 1993). Since SW13 cells contain coiled bodies, we performed double immunofluorescence microscopy with monoclonal anti-p80 coilin antibodies and guinea pig antiXenopus vimentin antibodies followed by CLSM (Fig. 5B). Thus, RNA, coiled bodies and vimentin filaments were colocalized, indicating that they occupy the same extrachromosomal nuclear compartment. The fact that not all 
Fig. 3. Analysis of the spatial relationship between the nuclear vimentin and delineated chromosome territories. (A) Confocal sections taken through a transfected SW13 nucleus at $0.5 \mu \mathrm{m}$ increments. Vimentin (red) and chromosome 1 sequences (green) have been delineated by indirect immunofluorescence and FISH, respectively. Bar, $10 \mu \mathrm{m}$. (B) A schematic diagram demonstrating the segmentation of chromosomal territories for the analysis of the localization of vimentin filaments. Confocal mid-sections of chromosomal territories were segmented so that the interior and peripheral portions were created. Three segments were assigned: segment 1 , representing the interior of the interphase chromosome; segment 2 , representing the outmost 3 pixels of the territory, and segment 3 , representing 3 pixels $(260 \mathrm{~nm})$ of the area immediately adjacent to the territory. Segments 2 and 3 togther represent the periphery (surface) of the chromosome. It was found that each region represented approximately $50 \%$ of the area of a delineated chromosome. A vimentin structure was scored as being situated in the segment of the lowest number when one pixel of the staining was within that area. This method (biased against our hypothesis) of scoring was chosen since the morphology of the vimentin filaments varies and it would be difficult to define the center of gravity for some structures. (C) Graphical representation of the analysis of the spatial relationship between the nuclear vimentin filaments and territories of chromosomes 1, 4, 8 and 13 . The numbers of territories analyzed for chromosomes 1, 4, 8 and 13 were 77, 80, 82 and 65, respectively $(n=304)$. The percentage of territories with vimentin within segment 1 was, for chromosomes $1,4,8$ and $13,18 \%, 14 \%, 22 \%$ and $12 \%$, respectively, within segment $2,21 \%, 31 \%, 24 \%$ and $25 \%$, respectively, and within segment $3,61 \%, 55 \%, 54 \%$ and $63 \%$, respectively, thus indicating that vimentin filamentous structures are preferentially located at the periphery of chromosomal territories.

RNA and coiled body signals colocalize with vimentin indicates that the vimentin arrays do not occupy the entire compartment, which is in concordance with the variable expression of nuclear-targeted vimentin (see Discussion).

In addition to coiled bodies, there are a number of antigenetically-variant nuclear bodies, such as PML bodies containing Sp100, PML and NDP52 antigens (Korioth et al., 1995, and references therein). In double immunofluorescence studies with anti-Xenopus vimentin antibody and a monoclonal anti-PML antibody, colocalization between nuclear vimentin and PML bodies was observed (Fig. 5C). This result suggests that PML bodies are also localized outside of chromosome territories. Hence, the intranuclear localization of PML bodies

Fig. 4. Vimentin filamentous arrays lie between two adjacent chromosome territories. A confocal section employing a biotinylated chromosome 4 probe and detected via avidin-FITC (displayed in pseudocolor blue). The chromosome 13 probe was labeled with digoxigenin and detected via anti-digoxigenin-TRITC (displayed in green); goat-anti-mouse antibody conjugated to fluorochrome cyanine-5 was used to visualize the Xenopus vimentin monoclonal antibody (displayed in red). The nuclear background, to show the nuclear outline, is pseudo colored ochre. Bar, $5 \mu \mathrm{m}$. with respect to chromosome territories was analyzed and determined by indirect immunofluorescence in combination with FISH employing a chromosome 4-specific painting probe. In analogy to our previous studies we analyzed primary male human dermal fibroblasts (Fig. 5D). Analysis of the spatial

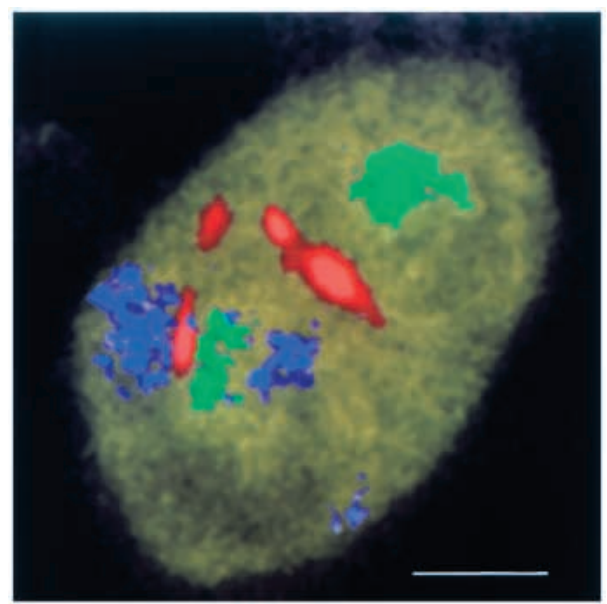


relationship of PML bodies with chromosome territories was performed as previously described (see Fig. 3), except that the center of each PML body was used to determine which segment of the chromosome territory the PML body was situated within. We found that for $92 \%$ of territories the center of the anti-PML staining was within the periphery of the territories while $8 \%$ was within the interior of the territories $(n=50)$, indicating that PML bodies are preferentially found at the border or outside of chromosome territories (Fig. 5E). These results are similar to data from analyses performed on female human dermal fibroblasts, analysing chromosomes X (inactive), 9 and 13 (M. Grande and R. van Driel, personal communication). It has been suggested that PML bodies interact with genes (de Jong et al., 1996). Since active and inactive genes are situated at the border of chromosome territories (Kurz et al., 1996), it is not surprising that PML bodies are mostly situated at the outside of the territories. In summary, the data show that extrachromosomal RNA, coiled bodies and PML bodies reside in the same nuclear compartment as the vimentin filamentous arrays.

\section{Nuclear vimentin filaments disassemble during mitosis and can reform in the same nuclear compartment after mitosis}

In the previous experiments it was shown that the nuclear vimentin filaments are localized outside of chromosome territories and are found in the same nuclear compartment as other extrachromosomal nuclear entities. Since this, to some extent, is an artificial system and vimentin filaments are forming in a nuclear environment which has already been organized after mitosis, we wished to determine whether the vimentin filaments could reform in the same nuclear compartment in cells which go through a mitotic division. Therefore, SW13 clone 14 cells were transferred to $28^{\circ} \mathrm{C}$ for 6 hours to allow vimentin filamentous arrays to form. Mitotic cells were dislodged by 'mitotic shake-off' and the resulting cells were replated at $28^{\circ} \mathrm{C}$. Samples of cells were fixed in $4 \%$ paraformaldehyde at various times (0-18 hours) after replating (Fig. 6A-I) and processed for vimentin immunodetection and nucleic acid staining. The vimentin filaments were disassembled during mitosis (Fig. 6A-B) yielding dense granular structures between chromosomes as well as a homogeneous background staining. The granules resembled vimentin structures observed in vimentin-containing mitotic cells (Franke et al., 1984). Since the nuclear lamina is thought to be disassembled by the action of serine/threonine protein kinase at the onset of mitosis (Peter et al., 1990), as has been shown to occur with cytoplasmic vimentin filaments (Chou et al., 1991), we assume that the nuclear vimentin filaments are disassembled by a similar mechanism. During anaphasetelophase, filaments started to reassemble on the chromosomal surfaces (Fig. 6C). At 1 hour after 'mitotic shake-off', vimentin was still partially localized in the cytoplasm, in addition to nuclear foci (Fig. 6D). With time, filamentous structures started to reform and appeared to be arranged as short filamentous arrays, indicating that vimentin was recruited and converted into an assembly competent form within the reforming nuclei. This is reminiscent of the processes which occur during the assembly of the nuclear lamina, involving mechanisms of modification and topologically ordered assembly. From 6 hours onwards, extensive filament systems were observed, as previously seen in interphase cells shifted to $28^{\circ} \mathrm{C}$ for 6 hours
(Fig. 6E-I). These data show that cells can proliferate in the presence of NLS-vimentin filaments and that nuclear vimentin filaments are reorganized during metaphase and reassemble in the nucleus after mitosis.

To determine whether the vimentin filaments, which had formed after mitosis, were still extrachromosomal, cells from the 'mitotic shake-off' were processed after 6 hours for FISH and immunofluorescence. In segmented territories of chromosome 4, $17 \%$ contained anti-vimentin staining within the interior region (segment 1) and $83 \%$ at the periphery of territories (segments 2 and 3 ). These data are very similar to the values found for chromosome 1, 4, 8 and 13 in cells which have not been through mitosis at the non-permissive temperature (see Fig. 3C). Since the vast majority of cells have vimentin at the periphery of territories, we conclude that mitotic cells organize vimentin filaments, de novo, in the same nuclear compartment as cells which have imported the protein during interphase.

\section{DISCUSSION}

Despite the increasing number of studies describing chromatinfree nuclear domains, the existence and extent of such a compartment is still a matter of debate (van Driel et al., 1995, and references therein). It has been difficult to delineate such a compartment by visualization of endogenous factors, although the existence of an interconnected network of snRNP accumulations has been proposed (Spector, 1990). The introduction of filament forming components, as performed in our study, has distinct advantages as compared to the use of soluble factors, since the latter are easily extracted during fixation procedures. The use of cells stably transfected with the temperature-sensitive amphibian NLS-vimentin permitted the analysis of its distribution in two interconvertable states. At $37^{\circ} \mathrm{C}$, a varying number of spherical aggregates were formed throughout the nucleus (outside of chromosome territories, data not shown). By shift of the growth temperature to $28^{\circ} \mathrm{C}$, the optimal temperature for Xenopus vimentin filament assembly (Herrmann et al., 1993), filaments started to grow in the nucleoplasm, apparently elongating from these aggregates into accessible space, so that by one hour short fibrils were observed, extending further in the next few hours. Indeed, this mode of filament formation may be an important property for the investigation of a topologically dynamic compartment, since growing cytoplasmic intermediate filaments are known to avoid intracellular barriers (Franke et al., 1978a,b). Even if there would be some active opening of a space involved, this would probably occur at, and therefore indicate, areas of diminished chromatin density.

The $28^{\circ} \mathrm{C}$-induced Xenopus vimentin filamentous system within the mammalian cell nucleus is principally different in morphology, when compared to networks of intermediate filaments in the cytoplasm. As shown by electron microscopy, the filamentous arrays of vimentin in the nucleoplasm of SW13 cells are comprised of filaments organized into bundles with no indication of interconnections between the filaments. The nuclear filamentous arrays are mostly curvilinear in morphology and in some cases there are large side branches which appear to originate from major accumulations of vimentin. In addition, vimentin structures can be seen as loops 
or rings. In the cytoplasm, endogenous vimentin rarely forms parallel bundles, but transverses cellular space in an apparently random, wavy fashion not forming loops or rings (Franke et al., 1978a,b). Taken together, these data imply that the morphology of the vimentin system is influenced, if not governed, by the nuclear environment.

In this study, we have shown that the introduced nuclear vimentin filaments are organized in the interchromosomal space, permitting the delineation of an extensive nuclear compartment inbetween the interphase chromosomes. Vimentin intermediate filaments are known to be highly flexible structures (see Fig. 4b in Hofmann et al., 1991). Therefore, they should easily follow spatial changes made by the interchromosomal compartment. It is plausible that the vimentin filaments are not filling up the entire extrachromosomal compartment, since the extent of the system varies from cell-to-cell. However, the three-dimensional reconstructions have revealed that the filament bundles can extensively traverse the nuclear interior.

Filamentous, as well as crystalline, unidentified intranuclear inclusions have been found in various cell types in both normal and pathological states, especially during viral infections. Thus, functional nuclei may contain and tolerate extensive filamentous material (Fukui, 1978; Ghadially et al., 1988). In several experimental situations, intermediate filament proteins have been observed to enter the cell nucleus forming extensive fibrillar arrays. Bader et al. (1991) showed that tail-deleted cytokeratins formed extensive intermediate filament bundles in the nucleoplasm. These fiber bundles extended for 10-20 $\mu \mathrm{m}$ being $0.1 \mu \mathrm{m}$ in diameter and apparently consisted of aligned individual filaments. These fibers never colocalized with lamin-positive structures. In other studies, tail-less Xenopus vimentin was observed to enter the nucleus, in some stable cell lines. Because of the thermosensitivity of the vimentin for filament assembly at $37^{\circ} \mathrm{C}$, it was deposited in small granules throughout the nucleus (Eckelt et al., 1992; Rogers et al., 1995). In a third line of experiments, after expression of epidermal keratins in transgenic mice, fibrillar material was found in nuclei of pancreatic islet $\beta$-cells. Electron microscopic analysis demonstrated that these intermediate filament bundles were approximately $0.1 \mu \mathrm{m}$ in width. In these three different situations and cell types, seemingly similar nuclear structures were found, indicating that certain topological requirements put a constraint on the nuclear organisation of such intermediate filaments. The spatial restrictions are further emphasized by the fact that cytoplasmic vimentin intermediate filaments do not usually form oriented bundles, indicating that the nuclear topology forces them to polymerize with a colinear orientation.

Although both vimentin and nuclear lamins are intermediate filament proteins (subtypes III and V, respectively), they contain considerable differences in their alpha-helical rod domain and do not coassemble in vivo (Moir et al., 1994; Monteiro et al., 1994; Schmidt et al., 1994). By performing costaining studies, we have shown that vimentin was not colocalized with the lamina at the nuclear periphery but was found throughout the nucleoplasm (Fig. 1C and E). In the large number of cells $\left(>10^{3}\right)$ analyzed during the current study, vimentin filaments were never observed extensively subjacent to the nuclear envelope, following the contours of the nuclear periphery. This indicates that even though vimentin is organized in an extrachromosomal compartment, there is no accessible space between chromosomes and the nuclear periphery, possibly due to the association of chromatin with the nuclear envelope. This observation is in agreement with other studies which have indicated that chromosomes are attached and anchored to the nuclear envelope/lamina (Borden and Manuelidis, 1988; Paddy et al., 1990; Belmont et al., 1993; Marshall et al., 1996).

Foci of nuclear lamin proteins have been observed deep within nuclei at different cell cycle times (Goldman et al., 1992; Bridger et al., 1993). Furthermore, using immunoelectron microscopy, lamin-type intermediate filaments have been observed ramifying through the nucleoplasm (Hozak et al., 1995). The diffuse intranuclear anti-lamin staining seen in these studies by light microscopy in permeabilized, DNase digested cells is distinctly different from the bright anti-vimentin filamentous structures, with very little background, also seen in similarly prepared cells (data not shown). The confined antivimentin staining cannot be attributed to reduced antibody penetration into chromosome territories, since staining from antibodies reacting with chromosomal proteins is found deep within interphase chromosomes (unpublished data). Hence, there is no indication that the Xenopus vimentin is incorporated into an intermediate filament-type nucleoskeleton.

There have been a number of track-like structures reported in cells in situ resembling the NLS-vimentin distribution. Some species of RNA are distributed in elongated accumulations (Lawrence et al., 1989; Raap et al., 1991; Huang et al., 1994). There is good evidence that such RNA accumulations consist of released transcripts, compatible with the concept that these RNAs are channeled to the nuclear envelope (Xing et al., 1995; Dirks et al., 1997; Lampel et al., 1997). Curvilinear proteinaceous tracks have also been observed in nuclei of cells using immunoelectron microscopy, such as the nucleolar protein Nopp 140 in rat liver cells and the HIV-1 nef in human T-cells. Nopp140 has been hypothesized to shuttle along the 'tracks' from nucleoli to the nuclear pores (Meier and Blobel, 1992). The HIV-1 nef tracks extend from the nuclear envelope deep into the nucleoplasm (Murti et al., 1993). These structures indicate that the respective proteins are confined to a highly specified area. Furthermore, the Tpr protein (translocated promoter region), in Xenopus oocytes, is organized into filaments which extend from nuclear pores into the nucleoplasm and can be observed in association with nucleoli (Cordes et al., 1997). The authors speculate that these filaments may have a role in the channeling of proteins or RNPs through the nucleoplasm. Accordingly, a recent study of Drosophila embryo nuclei demonstrated that a tpr-like protein was distributed throughout the nucleoplasm in a network between chromosomes (Zimowska et al., 1997). In dinoflagellate cells, actin has also been localized to an interchromosomal compartment in both mitosis and interphase (Soyer-Gobillard et al., 1996). Even though endogenous proteins have been observed, between chromosomes in these organisms, the existence of a continuous interchromosomal compartment has not been experimentally demonstrated.

We have shown that the NLS-vimentin filament system constitutes itself outside of chromosomes and colocalizes with nuclear components which are also located outside of chromosomes in interphase, such as nuclear RNA, coiled 
Fig. 5. Nuclear vimentin is colocalized with nuclear RNA, coiled bodies and PML bodies, which are situated outside of chromosome territories. All images are confocal optical sections. (A) A SW13 cell with detection of RNA derived from the Xenopus vimentin construct delineated by FISH using a specific biotinylated probe with conditions which only denature RNA and not DNA. Two RNA signals are found in this nucleus: one is green showing no colocalization with vimentin (red) and one is yellow where it is colocalized with the vimentin signal. A small amount of green fluorescence can be seen in the cytoplasm, representive of vimentin RNA. (B) A SW13 cell nucleus showing monoclonal anti-p80 coilin antibody staining delineating coiled bodies (green) and vimentin staining in red. Both coiled bodies are colocalized with the vimentin (yellow). (C) A SW13 cell nucleus where PML bodies have been revealed with monoclonal anti-PML antibody 5E10 (green), one is colocalized with the vimentin signal (red) hence the yellow coloration and one is not (green). (D) A tetraploid male human dermal fibroblast with territories of chromosome 4 (green) and anti-PML staining in red. Note the lack of colocalization of the two nuclear structures. Bars, $5 \mu \mathrm{m}$. (E) Graphical representation of the spatial relationship between the PML bodies and chromosomal territories. Territories of chromosome 4 have been segmented as described for Fig. 3 and the spatial positioning of PML bodies analyzed by taking the mid-point for the spherical structures; it was then determined whether they distributed to segment 1 (interior) or segments 2 and 3 (periphery). The percentage of territories with PML bodies situated within segment 1 was $8 \%$, within segment 2 was $18 \%$ and within segment 3 was $74 \%(n=50)$.
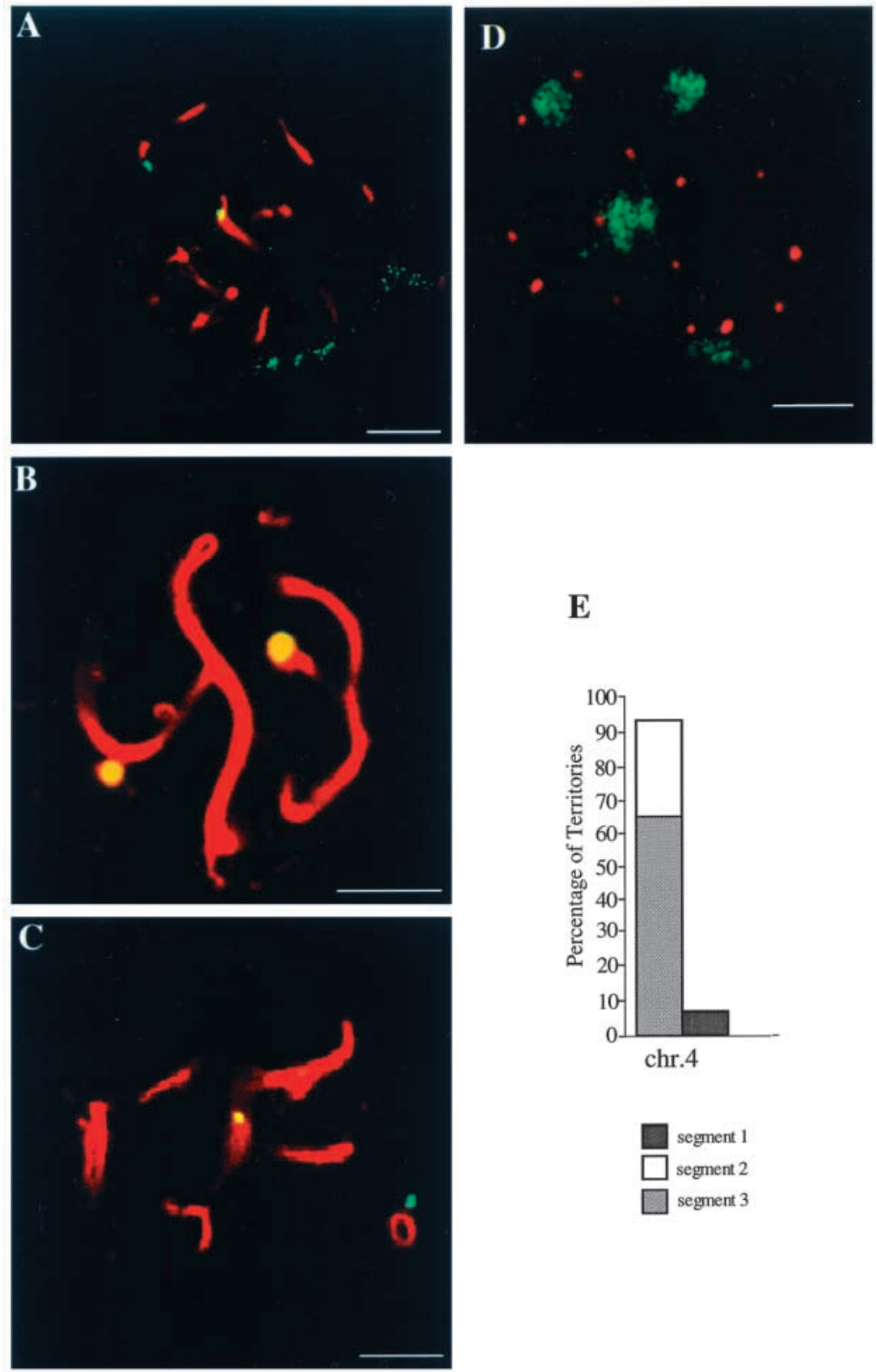

$\mathbf{E}$

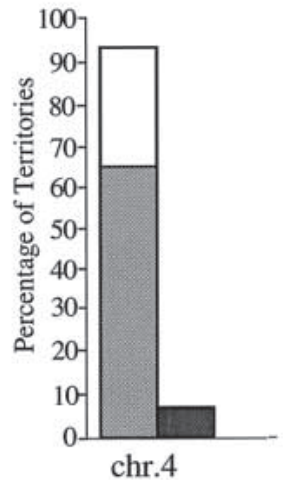

segment 1

segment 2

segment 3 bodies and PML bodies. It had been hypothesized, that these components occupy the same nuclear compartment, termed interchromosome domain (ICD) compartment. Since the space occupied by NLS-vimentin interconnects these components, it provides a means to partially visualize the ICD space. These findings do not preclude the existence of a dynamic nuclear matrix or skeleton. Indeed, splicing components (Ciejek et al., 1982; Zeitlin et al., 1987; Blencowe et al., 1994; Mattern et al., 1996), RNA (Mariman et al., 1982; Fey et al., 1986; He et al., 1990; Xing and Lawrence, 1991) and active genes (Robinson et al., 1983; Razin et al., 1985; Buttyan and Olsson, 1986), which are found at the periphery of chromosome territories (Zirbel et al., 1993; Kurz et al., 1996), are major components of the insoluble filamentous nuclear structure observed in nuclear matrix preparations. Hence, the nuclear structure observed by electron microscopy in extracted cells could be the accumulation of components of the nucleus which are distributed in the ICD compartment (Zirbel et al., 1993; Cremer et al., 1993, 1995). The view of an in vivo matrix as a dynamic, channeled network throughout the nucleus has also been put forward by others (Razin and Gromova, 1995; van Driel et al., 1995). While it still has to be determined how much the various nuclear networks define different entities, or overlap at least partially, the nuclear expression of exogeneous vimentin provides an experimental assay to address the spatial relationships among extrachromosomal nuclear components. In addition, it could serve as a useful 
Fig. 6. Localization of nuclear vimentin to visualize the reorganization of the interchromosomal compartment after mitosis. In this experiment, $\mathrm{SW} 13$ cells were incubated at $28^{\circ} \mathrm{C}$ for 6 hours after which time a 'mitotic shake-off' was performed. Cells were replated at $28^{\circ} \mathrm{C}$ and fixed at various time-points after shake-off. Confocal sections of representive mitotic cells. Nucleic acids are stained with propidium iodide (red) and the vimentin visualized after immunostaining (green). $(\mathrm{A}, \mathrm{B}, \mathrm{C})$ Cells in late prophase, metaphase and telophase, respectively. In A and $\mathrm{B}$ ( 0 hours) extensive vimentin staining is observed homogenously distributed throughout the mitotic cytoplasm, apparently in a mostly non-filamentous organization. In A and B and in particular $\mathrm{C}$ (0.5 hours) there are some aggregations of vimentin visible, possibly representing already formed filament bundles (seen as yellow). (D and E) In early $G_{1}$ cells, 1 and 2 hours after replating, rounded aggregates of vimentin are visible. Note that in (E) the cytoplasmic vimentin staining has disappeared. (F) SW 13 cells 3 hours after replating: the extension of the aggregates has begun and short filamentous arrays are present. (G and H) SW13 cells 6 hours after replating and arrays of vimentin can be observed. The two images are representative of pairs of cells displaying different thickness of filamentous structures. (I) An SW13 cell nucleus 18 hours after replating displaying an extensive vimentin system. The propidium iodide prefentially stains RNA and hence the nucleoli (in D-I) and the pre-nucleolar bodies (in D-F) are prominent. The vimentin filaments do not enter the nucleolar subcompartment of the nucleus and in some areas they follow the contours of the nucleoli. Bar, $10 \mu \mathrm{m}$.

tool to shuttle a wide range of proteins or peptides in order to test various subdomains for interaction partners in the nucleus, allowing associating entities to be isolated. Such a technique could represent an in vivo method analogous, and complementary, to the yeast two hybrid system.

We thank the following scientists at the German Cancer Research Center: A. Mincheva for support with cytogenetic analysis, S. Lampel and Ruthild Weber for help with the image analysis, H. Spring for CLSM three color images, C. Grund for performing electron microscopy, and D. Olins and W. W. Franke for critical reading of the manuscript and valuable discussions. We are very grateful for anti-p80 coilin monoclonal antibody from A. Lamond (Dundee) and anti-PML monoclonal antibody from R. van Driel (Amsterdam). This work was supported by a grant from the Deutsche Forschungsgemeinschaft (grant He 1853 to H.H.) and the BMBF 'Förderkonzept Humangenomforschung' (01KW9620 to P.L.).

\section{REFERENCES}

Ascoli, C. A. and Maul, G. G. (1991). Identification of a novel nuclear domain. J. Cell Biol. 112, 785-795.

Bader, B. L., Magin, T. M., Freudenmann, M., Stumpp, S. and Franke, W. W. (1991). Intermediate filaments formed in de novo from tail-less cytokeratins in the cytoplasm and in the nucleus. J. Cell Biol. 115, 12931307.

Belmont, A. S., Zhai, Y. and Thilenius, A. (1993). Lamin B distribution and association with peripheral chromatin revealed by optical sectioning and electron microscopy tomography. J. Cell Biol. 123, 1671-1685.

Berezney, R. and Jeon, K. W. (1995). Structural and functional organization of the nuclear matrix. International Review of Cytology, vol. 162A,B. Academic Press, New York.

Blencowe, B. J., Nickerson, J. A., Issner, R., Penman, S. and Sharp, P. A. (1994). Association of nuclear matrix antigens with exon-containing splicing complexes. J. Cell Biol. 127, 593-607.

Blessing, M., Rüther, U. and Franke, W. W. (1993). Ectopic synthesis of epidermal cytokeratins in pancreatic islet cells of transgenic mice interferes with cytoskeletal order and insulin production. J. Cell Biol. 120, 743-755. 
Borden, J. and Manuelidis, L. (1988). Movement of the X chromosome in epilepsy. Science 242, 1687-1691.

Bridger, J. M., Kill, I. R., O'Farrell, M. K. and Hutchison, C. J. (1993). Internal lamin structures within $\mathrm{G}_{1}$ nuclei of human dermal fibroblasts. $J$. Cell Sci. 104, 297-306.

Bridger, J. M., Lampel, S. and Lichter, P. (1997). Fluorescence in situ hybridization. In Cell Biology: A Laboratory Manual (ed. D. Spector, R. Goldman and L. Leinwand), pp. 111.1-111.45. Cold Spring Harbor Laboratory Press, NY.

Buttyan, R. and Olsson, C. A. (1986). Prediction of transcriptional activity based on gene association with the nuclear matrix. Biochem. Biophys. Res. Commun. 138, 1334-1340.

Carter, K. C., Taneja, K. L. and Lawrence, J. B. (1991). Discrete nuclear domains of poly(A) RNA and their relationship to the functional organization of the nucleus. J. Cell Biol. 115, 1191-1202.

Chai, L. S. and Sandberg, A. A. (1988). Chromosomes and their relationship to nuclear components during the cell cycle in Chinese hamster cells. Cell Tissue Res. 251, 197-204.

Chou, Y. H., Ngai, K. L. and Goldman, R. (1991). The regulation of intermediate filament reorganization in mitosis. J. Biol. Chem. 266, 73257328

Ciejek, E. M., Nordstrom, J. L., Tsai, M. J. and O’Malley, B. W. (1982). Ribonucleic acid precursors are associated with the chick oviduct nuclear matrix. Biochemistry 21, 4945-4953.

Clemson, C. M., McNeil, J. A., Willard, H. F. and Lawrence, J. B. (1996) XIST RNA paints the inactive $\mathrm{X}$ chromosome at interphase: evidence for a novel RNA involved in nuclear/chromosome structure. J. Cell Biol. 132, 259-275.

Collins, C., Kuo, W. L., Segraves, R., Fuscoe, J., Pinkel, D. and Gray, J. (1991). Construction and characterization of plasmid libraries enriched in sequences from single human chromosomes. Genomics 11, 997-1006.

Cordes, V. C., Reidenbach, S., Rackwitz, H. R. and Franke, W. W. (1997). Identification of protein $\mathrm{p} 270 / \mathrm{Tpr}$ as a constitutive component of the nuclear pore complex-attached intranuclear filaments. J. Cell Biol. 136, 515-529.

Cremer, T., Kurz, A., Zirbel, R., Dietzel, S., Rinke, B., Schröck, E., Speicher, M. R., Mathieu, U., Jauch, A., Emmerich, P., Scherthan, H., Ried, T., Cremer, C. and Lichter, P. (1993). The role of chromosome territories in the functional compartmentalization of the cell nucleus. Cold Spring Harbor Symp. Quant. Biol. 58, 777-792.

Cremer, T., Dietzel, S., Eils, R., Lichter, P and Cremer, C. (1995) Chromosome territories, nuclear matrix filaments and interchromatin channels: a topological view on nuclear architecture and function. Royal Botanic Gardens, Kew. 1, 63-81.

Daniel, M. T., Koken, M., Romagne, O., Barbey, S., Bazarbachi, A., Stadler, M., Guillemin, M.C., Degos, L., Chomienne, C. and de The, H. (1993). PML protein expression in hematopoietic and acute promyelocytic leukemia cells. Blood 82, 1858-1867.

de Jong, L., Grande, M. A., Mattern, K. A., Schul, W. and van Driel, R. (1996). Nuclear domains involved in RNA synthesis, RNA processing and replication. Crit. Rev. Euk. Gene Express. 6, 215-246.

Dirks, R. W., de Pauw, E. S. D. and Raap, A. K. (1997). Splicing factors associate with nuclear HCMV-IE transcripts after transcriptional activation of the gene, but dissociate upon transcription inhibition: evidence for a dynamic organization of splicing factors. J. Cell Sci. 110, 515-522.

Eckelt, A., Herrmann, H. and Franke, W. W. (1992). Assembly of a tailless mutant of the intermediate filament protein, vimentin, in vitro and in vivo. Eur. J. Cell Biol. 58, 319-330.

Fakan, S., Leser, G. and Martin, T. E. (1984). Ultrastructural distribution of nuclear ribonucleoproteins as visualized by immunocytochemistry on thin sections. J. Cell Biol. 98, 358-363.

Fey, E. G., Kochmalnic, G. and Penman, S. (1986). The nonchromatin substructures of the nucleus: The ribonucleoprotein (RNP)-containing and RNP-depleted matrices analyzed by seqential fractionation and resinless section electron microscopy. J. Cell Biol. 102, 1654-1665.

Franke, W. W., Grund, C., Kuhn, C., Lehto, V. P. and Virtanen, I. (1984) Transient change of organization of vimentin filaments during mitosis as demonstrated by a monoclonal antibody. Exp. Cell Res. 154, 567-580.

Franke, W. W., Grund, C., Osborn, M. and Weber, K. (1978a). The intermediate-sized filaments in rat kangaroo PtK2 cells. I. Morphology in situ. Eur. J. Cell Biol. 17, 365-391.

Franke, W. W., Schmid, E., Osborn, M. and Weber, K. (1978b). Different intermediate-sized filaments distinguished by immunofluorescence microscopy. Proc. Nat. Acad. Sci. USA 75, 5034-5038.
Fukui, Y. (1978). Intranuclear actin bundles induced by dimethyl sulfoxide in interphase nucleus of Dictyostelium. J. Cell Biol. 76, 146-157.

Ghadially, F. N., Killam, I. W. and Lindsay, W. S. (1988). Ultrastructural pathology of the cell and matrix. London, Butterworths.

Goldman, A. E., Moir, R. D., Montag-Lowry, M., Stewart, M. and Goldman, R. D. (1992). Pathway of incorporation of microinjected lamin A into the nuclear envelope. J. Cell Biol. 119, 725-735.

Gruenbaum, Y., Hochstrasser, M., Mathog, D., Saumweber, H., Agard, D. A. and Sedat, J. W. (1984). Spatial organization of the Drosophila nucleus: a three-dimensional cytogenetic study. J. Cell Sci. Suppl. 1, 223-234.

He, D. C., Nickerson, J. A. and Penman, S. (1990). Core filaments of the nuclear matrix. J. Cell Biol. 110, 569-580.

Hedburg, K. K. and Chen, L. B. (1986). Absence of intermediate filaments in a human adrenal cortex carcinoma-derived cell-line. Exp. Cell Res. 163, 509-517.

Herrmann, H., Hofmann, I. and Franke, W. W. (1992). Identification of a nonapeptide motif in the vimentin head domain involved in intermediate filament assembly. J. Mol. Biol. 223, 637-650.

Herrmann, H., Eckelt, A., Brettel, M., Grund, C. and Franke, W. W. (1993). Temperature-sensitive intermediate filament assembly. Alternative structures of Xenopus laevis vimentin in vitro and in vivo. J. Mol. Biol. 234 99-113.

Herrmann, H., Munick, M. D., Brettel, M., Fouquet, B. and Markl, J. (1996). Vimentin in a cold-water fish, the rainbow trout: highly conserved primary structure but unique assembly properties. J. Cell Sci. 109, 569578

Hochstrasser, M., Mathog, D., Gruenbaum, Y., Saumweber, H. and Sedat, J. W. (1986). Spatial organization of chromosomes in the salivary gland nuclei of Drosophila melanogaster. J. Cell Biol. 102, 112-123.

Hofmann, I., Herrmann, F. and Franke, W. W. (1991). Assembly and structure of calcium-induced thick vimentin filaments. Eur. J. Cell Biol. 58, 328-341.

Hozak, P., Sasseville, M. J., Raymond, Y. and Cook, P. R. (1995). Lamin proteins form an internal nucleoskeleton as well as a peripheral lamina in human cells. J. Cell Sci. 108, 635-644.

Huang, S., Deerink, T., Ellisman, M. and Spector, D. (1994). In vivo analysis of the stability and transport of nuclear poly(A)+ RNA. J. Cell Biol. 126, 877-899.

Jackson, D. A., Hassan, A. B., Errington, R. J. and Cook, P. R. (1993) Visualization of focal sites of transcription within human nuclei. EMBO J. 12, 1059-1065.

Jiménez-Garcia, L. F. and Spector, D. L. (1993). In vivo evidence that transcription and splicing are coordinated by a recruiting mechanism. Cell 73, 47-59.

Korioth, F., Gieffers, C., Maul, G. G. and Frey, J. (1995). Molecular characterization of NDP52, a novel protein of the nuclear domain 10, which is redistributed upon virus infection and interferon treatment. J. Cell Biol. 130, 1-13.

Kurz, A., Lampel, S., Nickolenko, J. E., Bradl, J., Benner, A., Zirbel, R. M., Cremer, T. and Lichter, P. (1996). Active and inactive genes localize preferentially in the periphery of chromosome territories. J. Cell Biol. 135 1195-1205.

Lacroute, P. and Levoy, M. (1994). Fast volume rendering using a shear-warp factorization of the viewing transformation. Computer Graphic Proceedings. ACM SIGGRAPH. Ann. Conf. Series, 451-458.

Lamond, A. I. and Carmo-Fonseca, M. (1993). The coiled body. Trends Cell Biol. 3, 198-204.

Lampel, S., Bridger, J. M., Zirbel, R. M., Mathieu, U. R. and Lichter, P. (1997). Nuclear RNA accumulations contain released transcripts and exhibit specific distributions with respect to Sm antigen foci. DNA Cell Biol. 16, 1133-1142.

Lawrence, J. B., Singer, R. H. and Marselle, L. M. (1989). Highly localized tracks of specific transcripts within interphase nuclei visualized by in situ hybridization. Cell 57, 493-502.

Lichter, P., Tang, C. C., Call, K., Hermanson, G., Evans, G. A., Housman, D. and Ward, D. C. (1990). High resolution mapping of human chromosome 11 by in situ hybridization with cosmid clones. Science $\mathbf{2 4 7}$ 64-69.

Lichter, P., Boyle, A. L., Cremer, T. and Ward, D. C. (1991). Analysis of genes and chromosomes by non-isotopic in situ hybridization. Genet. Anal. Technol. Appl. 8, 24-35.

Mariman, E. C., van Eekelen, C. A., Reidners, R. J., Berns, A. J. and van Venrooij, W. J. (1982). Adenoviral heterogeneous nuclear RNA is 
associated with the host nuclear matrix during splicing. J. Mol. Biol. 154 103-119.

Marshall, W. F., Dernburg, A. F., Harmon, B., Agard, D. A. and Sedat, J. W. (1996). Specific interactions of chromatin with the nuclear envelope: positional determination within the nucleus in Drosophila melanogaster. Mol. Biol. Cell 7, 825-842.

Mattern, K. A., Humbel, B. M., Muijsers, A. O., de Jong, L. and van Driel, R. (1996). hnRNP proteins and B23 are the major proteins of the internal nuclear matrix of HeLa S3 cells. J. Cell. Biochem. 62, 275-289.

Meier, U. T. and Blobel, G. (1992). Nopp140 shuttles on tracks between nucleolus and cytoplasm. Cell 70, 127-138.

Moir, R. D., Montag-Lowy, M. and Goldman, R. D. (1994). Dynamic properties of nulear lamins: lamin B is associated with sites of DNA replication. J. Cell Biol. 125, 1201-1212.

Monteiro, M. J., Hicks, C., Gu, L. and Janicki, S. (1994). Determinants for intracellular sorting of cytoplasmic and nuclear intermediate filaments. $J$. Cell Biol. 127, 1327-1343.

Murti, K. G., Brown, P. S., Ratner, L. and Garcia, J. V. (1993). Highly localized tracks of human immunodeficiency virus type $1 \mathrm{Nef}$ in the nucleus of cells of a human CD4+ T-cell line. Proc. Nat. Acad. Sci. USA 90, 1189511899.

Paddy, M. R., Belmont, A. S., Saumweber, H., Agard, D. A. and Sedat, J. W. (1990). Interphase nuclear envelope lamins form a discontinuous network that interacts with only a fraction of the chromatin in the nuclear periphery. Cell 62, 89-106.

Peter, M., Nakagawa, J., Doree, M., Labbe, J. C. and Nigg, E. A. (1990). In vitro disassembly of the nuclear lamina and $M$ phase-specific phosphorylation of lamins by cdc2 kinase. Cell 61, 591-602.

Quinlan, R. A., Hutchison, C. J. and Lane, E. B. (1995). Intermediate filament proteins. Protein Profile. 2, 795-952.

Raap, A. K., van de Rijke, F. M., Dirks, R. W., Sol, C. J., Bloom, R. and van der Ploeg, M. (1991). Bicolor fluorescence in situ hybridization to intron and exon mRNA sequences. Exp. Cell Res. 197, 319-322.

Razin, S. V. and Gromova, I. I. (1995). The channels model of nuclear matrix structure. BioEssays 17, 443-450.

Razin, S. V., Yarovaya, O. V. and Georgiev, G. P. (1985). Low ionic strength extraction of nuclease-treated nuclei destroys the attachment of transcriptionally active DNA to the nuclear skeleton. Nucl. Acids Res. 13, 7427-7444.

Robinson, S. I., Small, D., Idzerda, R., McKnight, G. S. and Vogelstein, B. (1983). The association of transcriptionally active genes with the nuclear matrix of the chicken oviduct. Nucl. Acids Res. 11, 5113-5130.

Rogers, K. R., Eckelt, A., Nimmrich, V., Janssen, K. P., Schliwa, M., Herrmann, H. and Franke, W. W. (1995). Truncation mutagenesis of the non-alpha-helical carboxyterminal tail domain of vimentin reveals contributions to cellular localization but not to filament assembly. Eur. J. Cell Biol. 66, 136-150.

Roth, M. B. (1995). Spheres, coiled bodies and nuclear bodies. Curr. Opin. Cell Biol. 7, 325-328.
Scheer, U. and Weisenberger, D. (1994). The nucleolus. Curr. Opin. Cell Biol. 6, 354-359.

Schmidt, M., Tschodrich-Rotter, M., Peters, R. and Krohne, G. (1994). Properties of fluorescently labeled Xenopus lamin A in vivo. Eur. J. Cell Biol. 65, 70-81.

Soyer-Gobillard, M.-O., Ausseil, J. and Géraud, M. L. (1996). Nuclear and cytoplasmic actin in dinoflagellates. Biol. Cell 87, 17-35.

Spector, D. L. (1990). Higher order nuclear organization: three-dimensional distribution of small nuclear ribonucleoprotein particles. Proc. Nat. Acad. Sci. USA 87, 147-151.

Spector, D. L., Fu, X.-D. and Maniatis, T. (1991). Associations between distinct pre-mRNA splicing components and the cell nucleus. EMBO J.10, 3467-3481.

Stewart, M. (1993). Intermediate filament structure and assembly. Curr. Opin. Cell Biol. 5, 3-11.

Stuurman, N., de Graaf, A., Floore, A., Josso, A., Humbel, B., de Jong, L. and van Driel, R. (1992). A monoclonal antibody recognizing nuclear matrix-associated nuclear bodies. J. Cell Sci. 101, 773-784.

Thiry, M. and Goessens, G. (1992). Where, within the nucleolus, are the rRNA genes located? Exp. Cell Res. 200, 1-4.

van Driel, R., Wansink, D. G., van Steensel, B., Grande, M. A., Schul, W. and de Jong, L. (1995). Nuclear domains and the nuclear matrix. Int. Rev. Cytol. 162A, 151-189.

Visa, N., Puvion-Dutilleul, F., Harper, F., Bachellerie, J.-P. and Puvion, E. (1993). Intranuclear distribution of poly(A) RNA determined by electron microscope in situ hybridization. Exp. Cell Res. 208, 19-34.

Wansink, D. G., Schul, W., van der Kraan, I., van Steensel, B., van Driel, R. and de Jong, L. (1993). Fluorescent labeling of nascent RNA reveals transcription by RNA polymerase II in domains scattered throughout the nucleus. J. Cell Biol. 122, 283-293.

Xing, Y. and Lawrence, J. B. (1991). Preservation of specific RNA distribution within the chromatin-depleted nuclear substructure demonstrated by in situ hybridization coupled with biochemical fractionation. J. Cell Biol. 112, 1055-1063.

Xing, Y., Johnson, C. V., Dobner, P. R. and Lawrence, J. B. (1993). Higher level organization of individual gene transcription and RNA splicing. Science 259, 1326-1330.

Xing, Y., Johnson, C. V., Moen, P. T., McNeil, J. A. and Lawrence, J. B. (1995). Nonrandom gene organization: structural arrangement of specific pre-mRNA transcription and splicing with SC-35 domains. J. Cell Biol. 131, 1635-1647.

Zeitlin, S., Parent, A., Silverstein, S. and Efstratiadis, A. (1987). Pre-mRNA splicing and the nuclear matrix. Mol. Cell. Biol. 7, 111-120.

Zimowska, G., Aris, J. P. and Paddy, M. R. (1997). A Drosophila Tpr protein homolog is localized both in the extrachromosomal channel network and to nuclear pore complexes. J. Cell Sci. 110, 927-944.

Zirbel, R. M., Mathieu, U. R., Kurz, A., Cremer, T. and Lichter, P. (1993). Evidence for a nuclear compartment of transcription and splicing located at chromosome domain boundaries. Chrom. Res. 1, 93-106. 